\author{
JURNAL EINSTEIN \\ Jurnal Hasil Penelitian Bindang Fisika \\ Available online http://jurnal.unimed.ac.id/2012/index.php/einsten \\ e-issn: $2407-747 x$, p-issn $2338-1981$
}

\title{
PENGARUH PENAMBAHAN ABU AMPAS TEBU DAN TEMPURUNG KELAPA TERHADAP KUAT TEKAN BETON
}

\author{
Nurhidayah P, Mara Bangun H *) \\ Jurusan Fisika, Fakultas Matematika dan Ilmu Pengetahuan Alam, Universitas Negeri Medan, \\ Indonesia \\ hidayahpanjaitan@gmail.com \\ Diterima Februari 2018; Disetujui Februari 2018; Dipublikasikan Februari 2018
}

\begin{abstract}
ABSTRAK
Penelitian ini bertujuan untuk mengetahui pengaruh penambahan abu ampas tebu dan tempurung kelapa terhadap kuat tekan beton. Penelitian ini dilakukan di Laboratorium beton teknik UNIMED mulai dari bulan Maret sampai dengan April 2017. Metode pembuatan yang dilakukan adalah SNI 03-2834-2000 yang mengacu pada pembuatan beton mutu K-175 dengan komposisi campuran semen : pasir : kerikil adalah $1: 2: 3$ dengan FAS 0,5. Beton dibuat berbentuk kubus $15 \times 15 \times 15 \mathrm{~cm}$.. Setelah beton berumur 24 jam cetakan dibuka dan diberi nomor kode sesuai yang diinginkan dan dirawat dalam bak air. Setelah melalui masa perendaman 28 hari kemudian beton diuji dengan metode uji kuat teka $\mathrm{n}$ dan daya serap air. Dari hasil pengujian diperoleh sifat mekanik yaitu kuat tekan beton minimum nya yaitu pada penambahan abu ampas tebu $4 \%$ dan tempurung kelapa $3 \%$ yaitu rata-rata $16,57 \mathrm{MPa}$, sedangkan kuat tekan beton maksimum yaitu pada penambahan abu ampas tebu $6 \%$ dan tempurung kelapa $4 \%$ yaitu rata-rata $18,05 \mathrm{MPa}$. Dari hasil pengujian daya serap air terjadi penurunan pada beton dengan penambahan $4 \%$ tempurung kelapa dan $6 \%$ abu ampas tebu (sampel C).
\end{abstract}

Kata Kunci : Beton Normal, Kuat Tekan Beton, Daya Serap Air.

\section{PENDAHULUAN}

Umumnya kekuatan beton dipengaruhi oleh kekuatan komponen penyusunnya yaitu pasta semen, rongga, agregat, dan interface antara pasta semen dengan agregat. Agregat itu sendiri menempati komposisi paling besar dalam pembuatan beton yaitu sekitar 70\%-80\%. Berdasar pada hal ini maka kemungkinan penggunaan agregat yang unggul atau yang mempunyai kandungan silika yang tinggi dalam pembuatan akan sangat baik untuk meningkatkan kuat tekan beton itu sendiri. Salah satu bahan alternatif yang digunakan dalam pembuatan beton normal adalah abu ampas tebu dan tempurung kelapa.

Pada penelitian ini serpihan serat tempurung kelapa yang digunakan dimensinya lebih kecil lagi, yaitu maksimal $\pm 5 \mathrm{~mm}$ agar dapat meminimalisir tereliminasinya massa/volume beton akibat penambahan tempurung kelapa tersebut, selain itu dengan dimensi yang lebih kecil pecahan tempurung kelapa dapat bekerja lebih sempurna sebagai filler (bahan pengisi) serta dapat meningkatkan kuat tekan beton. Variasi campuran yang direncanakan yaitu abu ampas tebu 4\%, 6\%, 8\% dan 3\%, 4\%. 5\% tempurung kelapa. 
Dasar dari penelitian ini adalah bagaimana memadukan semua material penyusun untuk mendapatkan beton yang unggul baik dari segi kuat tekan maupun dari berat elemen struktur beton. jika pemanfaatan tempurung kelapa dapat dibuktikan secara teknis sebagai bahan/agregat untuk campuran, maka diharapkan juga dapat mengurangi dampak pencemaran lingkungan dan mempunyai nilai tambah secara ekonomi bagi masyarakat. Ketelitian dalam pengerjaan dan perawatan akan lebih ditingkatkan untuk mendapatkan hasil yang lebih baik. Sehingga dari uraian diatas judul penelitian ini adalah "Pengaruh Abu Ampas Tebu dan Tempurung Kelapa Terhadap Kuat Tekan Beton”.

\section{METODE PENLITIAN}

Alat yang digunakan pada penelitian ini yaitu Mesin kuat tekan, neraca, ayakan, sendok semen, gelas ukur, mesin pengaduk, adah ember, perojok.

Bahan yang disiapkan semen portland type 1, agregat kasar (kerikil), agregat halus (pasir sungai), serbuk tempurung kelapa (\%, $4 \%$, $5 \%)$, abu ampas tebu $(4 \%, 6 \%, 8 \%)$, air, dan oli kotor.

Penelitian dilakukan dengan metode laboratorium dengan benda uji yang dibuat dari 4 (empat) kelompok yaitu: benda uji dengan menggunakan $0 \%$ tempurung kelapa tambah $0 \%$ abu ampas tebu sebagai beton normal, benda uji menggunakan $4 \%$ abu ampas tambah 3\% tempurung kelapa, benda uji menggunakan $6 \%$ abu ampas tambah $4 \%$ tempurung kelapa, benda uji menggunakan $8 \%$ abu ampas tambah 5\% tempurung kelapa.pengujian yang dilakukan yaitu pengujian kuat tekan dan pengujian daya serap air.

Metode penelitian yang telah dilakukan dalam pembuatan beton dengan campuran abu ampas tebu dan tempurung kelapa :

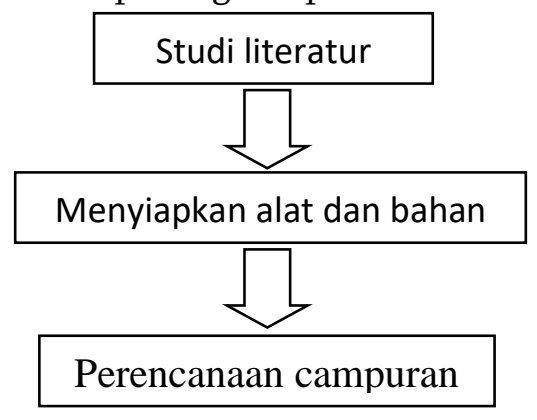

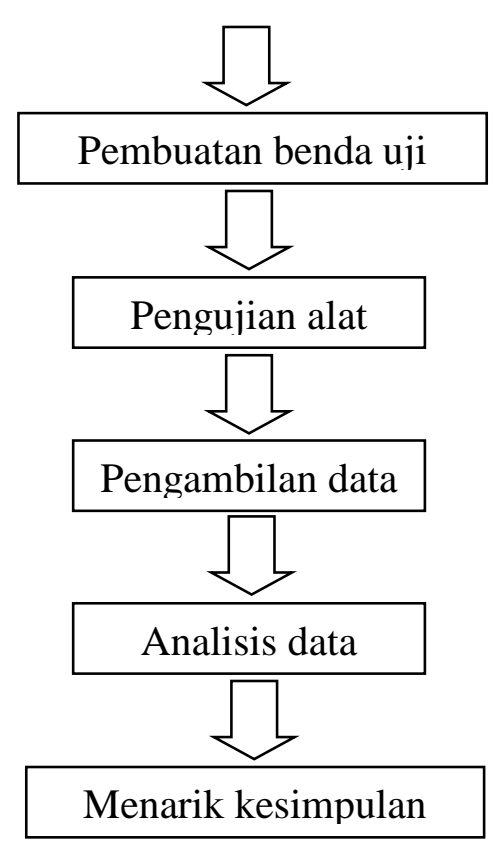

HASIL DAN PEMBAHASAN

Kuat tekan

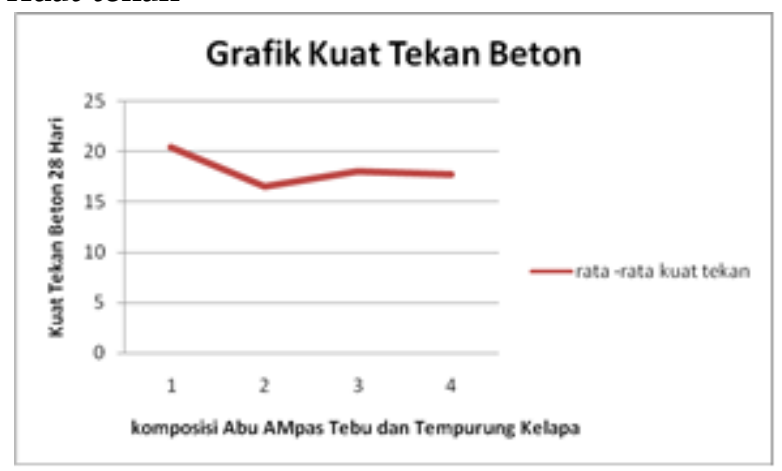

Gambar 1. grafik hubungan kuat tekan beto dengan campuran abu ampas tebu dan tempurung kelapa

Berdasarkan grafik di atas dapat dilihat bahwa beton dengan penambahan abu ampas tebu dan tempurung kelapa nilai uji tekannya mengalami penurunan dari beton normal. Kuat tekan rata - rata dari beton normal adalah 20.45, sedangkan kuat tekan tertinggi dari penambahan abu ampas tebu dan tempurung kelapa adalah pada sampel $\mathrm{C}$ yaitu dengan penambahan abu ampas tebu $6 \%$ dan tempurung kelapa $4 \%$ sebesar 18.05 Mpa. Kuat tekan terkecil adalah pada sampel B dengan penambahan abu ampas tebu $4 \%$ dan tempurung kelapa $3 \%$ sebesar 16.57 Mpa. 
Daya serap air

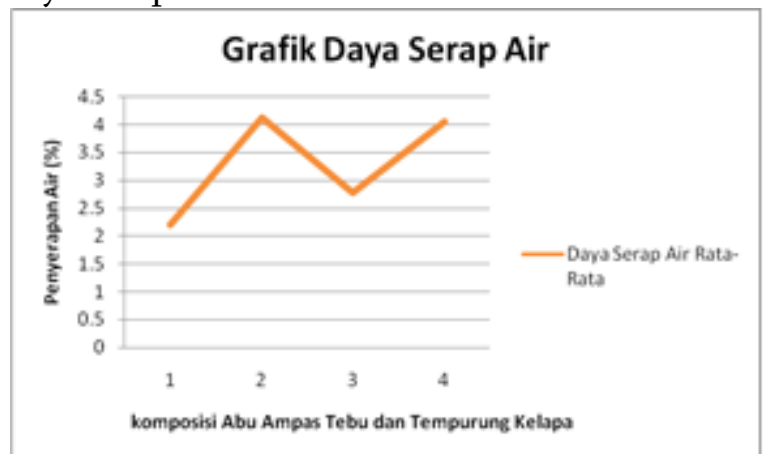

Gambar 2. grafik hubungan antara daya serap air dengan campuran abu ampas tebu dan tempurung kelapa

Daya serap air pada suatu beton dipengaruhi oleh adanya pori atau rongga . semakin banyak pori yang terkandung dalam beton maka semakin besar pula penyerapan sehingga ketahanan berkurang.

Pada gambar 3 diperoleh daya serap air rata-rata terendah pada komposisi beton dengan penambahan abu ampas tebu $0 \%$ dan tempurung kelapa $0 \%$ yaitu pada beton standar dengan nilai rata-rata 2.21. Pada penelitian ini daya serap air yang tertinggi diperoleh pada komposisi abu ampas tebu $4 \%$ dan tempurung kelapa 3\% dengan nilai rata-rata $4.12 \%$.

\section{KESIMPULAN DAN SARAN}

Dari hasil penelitian tentang pengaruh penambahan abu ampas tebu dan tempurung kelapa terhadap kuat tekan beton dapat disimpulkan sebagai berikut:

1. Kuat tekan yang dihasilkan dengan penambahan abu ampas tebu dan tempurung kelapa memberikan nilai lebih kecil dari kuat tekan yang direncanakan. Pada penelitian ini pengujian kuat tekan yang tetinggi diperoleh pada beton standar (abu ampas tebu $0 \%$ dan tempurung kelapa $0 \%$ ) yaitu sebesar $20.45 \mathrm{MPa}$. Sedangkan hasil pengujian kuat tekan beton dengan penambahan abu ampas tebu $4 \%$ ditambah tempurung kelapa $3 \%$, abu ampas tebu $6 \%$ ditambah tempurung kelapa $4 \%$, abu ampas tebu $8 \%$ ditambah tempurung kelapa 5\% masing-masing kuat tekannya adalah $16.57 \mathrm{MPa}, 18.05$ MPa, 17.79 Mpa.
2. Secara keseluruhan dengan mempertahankan penggunaan air dalam campuran beton diperoleh presentase optimal pada penambahan abu ampas tebu $6 \%$ dan tempurung kelapa $4 \%$, dikarenakan memiliki workbility yang cukup baik dibandingkan presentase yang lebih dari 5\%. Semakin besar penambahan abu ampas tebu maka semakin rendah workability campuran beton atau campuran beton semakin sulit untuk dikerjakan.

\section{DAFTAR PUSTAKA}

Akbar, (2013), Penggunaan Tempurung Kelapa Terhadap Kuat Tekan Beton K-100, Program Studi Teknik Sipil, Fakultas Teknik Universitas Pasir Pengaraian.

Mulyono, T., (2004), Teknologi Beton, ANDI, Yogyakarta

Suarnita, I Wayan., (2005), Kapasitas Lentur Balok Beton Bertulang dengan Styrofoam sebagai Pengganti Perekat, Jurnal SMARTek, Vol.3. No.1:1-11

Tjokromuljo, K., (1996), Teknologi Beton, Penerbit Nafigiri, Yogyakarta Maidayani, (2009), Pengaruh Aktif Lateks dan Komposisi Terhadap Karakteristik Beton dengan Menggunakan Limbah Padat (Slutge) Industri Kertas, Tesis, USU:Medan 